Check for updates

Cite this: Chem. Commun., 2017, 53,4726

Received 10th February 2017, Accepted 5th April 2017

DOI: $10.1039 / \mathrm{c} 7 \mathrm{cc} 01085 \mathrm{k}$

rsc.li/chemcomm

\section{Cobalt-catalysed Markovnikov selective hydroboration of vinylarenes $\dagger$}

\author{
Jingying Peng, ${ }^{a}$ Jamie H. Docherty, ${ }^{a}$ Andrew P. Dominey ${ }^{\mathrm{b}}$ and \\ Stephen P. Thomas (D)*a
}

\begin{abstract}
A bipyridiyl-oxazoline cobalt catalyst ${ }^{t}{ }^{\mathrm{Bu}} \mathrm{BPOCOCl}_{2}$ has been developed for the Markovnikov selective hydroboration of alkenes using pinacolborane and $\mathrm{NaO}^{t} \mathrm{Bu}$ as the in situ activator with up to $>98: 2$ branched : linear selectivity (24 examples, $45-92 \%$ isolated yield).
\end{abstract}

Metal-catalysed alkene hydroboration has received much attention, as the resulting boronic esters are versatile intermediates in the construction of various $\mathrm{C}-\mathrm{C}$ and $\mathrm{C}$-heteroatom bonds. ${ }^{1}$ The majority of metal-catalysed alkene hydroboration reactions involve complexes of precious metals, such as $\mathrm{Rh}, \mathrm{Ru}$ and $\mathrm{Ir}^{2}$ Although high chemoselectivity, regioselectivity, and enantioselectivity can be achieved, the low abundance and environmental concerns associated with these metals has driven investigations for Earth-abundant metal alternatives. ${ }^{3,4}$

In recent years, a number of Earth-abundant and base metal complexes have been developed for alkene hydroboration. In most cases, these reactions are either highly anti-Markovnikov selective or give a mixture of both Markovnikov and anti-Markovnikov products. $^{5-18}$ Huang reported that bipyridyl-phosphine cobalt complexes show high activity in the anti-Markovnikov hydroboration of alkenes. ${ }^{5}$ Additionally, Chirik developed bis(imino)pyridine cobalt methyl complexes for the anti-Markovnikov selective hydroboration of alkenes (Scheme 1A). ${ }^{6}$ Of direct significance to this manuscript, Chirik ${ }^{7}$ and Hollis ${ }^{8}$ have both reported unique cobalt catalysts capable of catalysing the Markovnikov selective hydroboration of styrene in 25:1 and 20:1 branched to linear ratio, respectively (Scheme 1B). Isomerisation-hydroboration using cobalt catalysis has also been reported by Chirik; which serves as an orthogonal procedure for the generation of branched boronic esters from aliphatic internal alkenes. ${ }^{9}$ However, a general reaction protocol with broad scope using a cobalt catalyst for the direct

\footnotetext{
${ }^{a}$ EaStCHEM School of Chemistry, University of Edinburgh, David Brewster Road, Edinburgh, EH9 3FJ, UK. E-mail: stephen.thomas@ed.ac.uk

${ }^{b}$ GSK Medicines Research Centre, Gunnels Wood Road, Stevenage, SG1 2NY, Hertfordshire, UK

$\dagger$ Electronic supplementary information (ESI) available. See DOI: 10.1039/ c7cc01085k
}

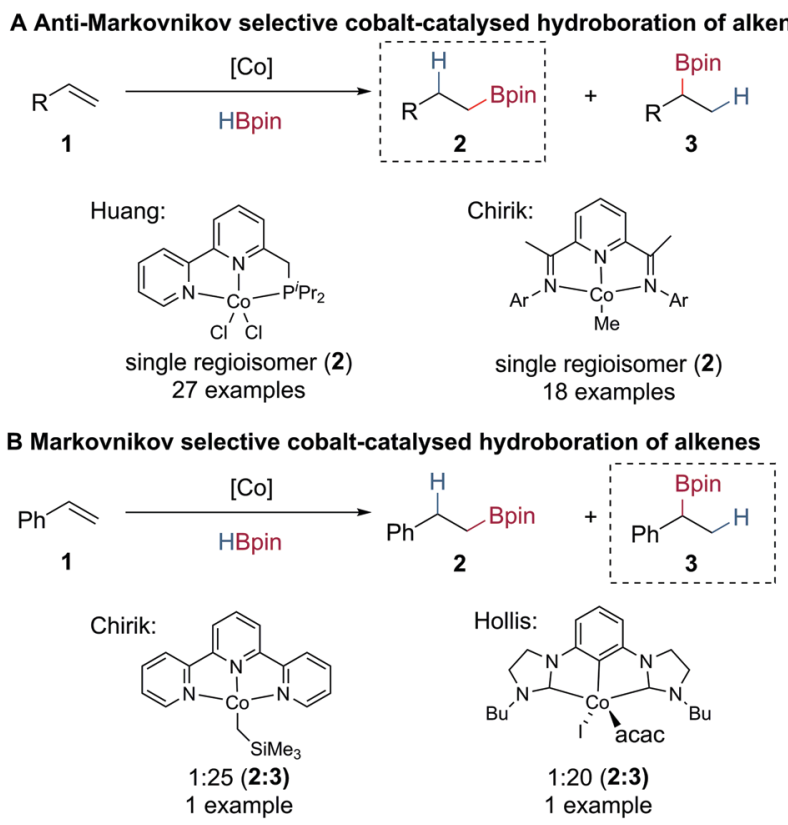

C This work: Highly selective Markovnikov hydroboration of alkenes

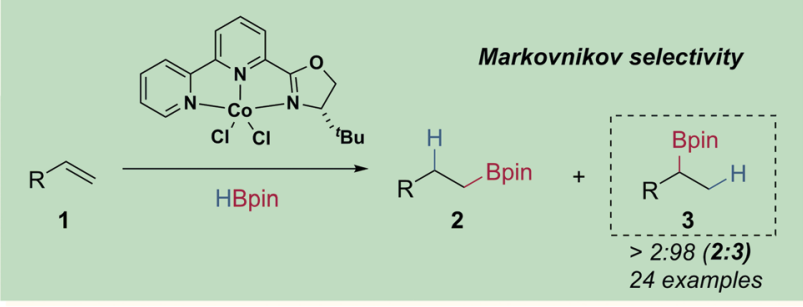

Scheme 1 (A) Anti-Markovnikov selective cobalt-catalysed alkene hydroboration. (B) Markovnikov selective cobalt-catalysed hydroboration of alkenes. (C) This work: ${ }^{t} \mathrm{Bu} B \mathrm{BPCOCl}{ }_{2}$-catalysed highly selective Markovnikov hydroboration of alkenes.

Markovnikov selective hydroboration of alkenes has not been disclosed.

Herein, we report the preparation of bipyridiyl-oxazoline cobalt(II) complexes and the application of these in cobalt-catalysed 

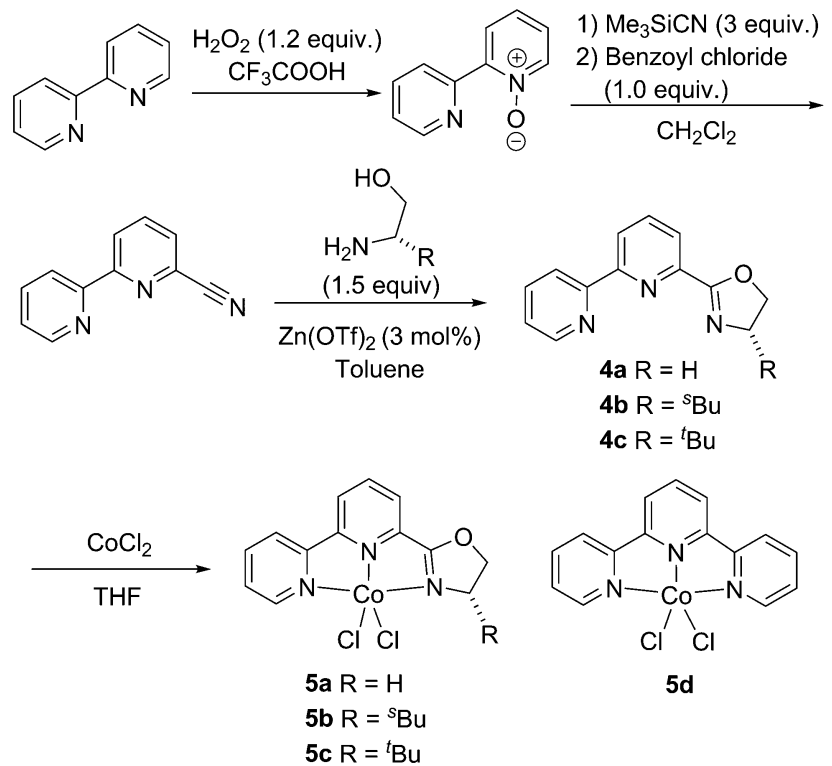

$5 b \mathrm{~b}={ }^{s} \mathrm{Bu}$

$5 \mathrm{c} R={ }^{t} \mathrm{Bu}$

Scheme 2 Synthesis of bipyridiyl-oxazoline cobalt complexes $\mathbf{5 a - 5 c}$ and terpyridine cobalt complex $\mathbf{5 d}$.

alkene hydroboration using $\mathrm{NaO}^{t} \mathrm{Bu}$ as the in situ pre-catalyst activator. ${ }^{18}$ This system presents a new and unique method for the generation of secondary boronic esters from readily available vinylarene starting materials with high regioselectivity, which is divergent from the majority of cobalt-catalysed alkene hydroboration reactions (Scheme 1C).

A series of cobalt complexes $\mathbf{5 a - 5 c}$ bearing novel bipyridiyloxazoline ligands was synthesised in four steps (Scheme 2). Reaction of 2,2'-bipyridine with hydrogen peroxide and trifluoroacetic acid gave 2,2'-bipyridine-1-oxide, which was reacted with trimethylsilyl cyanide and benzoyl chloride to give the bipyridylcarbonitrile compound. Condensation of the bipyridyl-carbonitrile with various amino alcohols in the presence of $\mathrm{Zn}(\mathrm{OTf})_{2}$ produced the bipyridiyl-oxazoline ligands $\mathbf{4 a - 4 c}$ in moderate yields. The neutral bipyridiyl-oxazoline cobalt(II) dichloride complexes $\mathbf{5 a - 5 c}$ were formed in high yield by the addition of the corresponding ligand to anhydrous cobalt dichloride in anhydrous tetrahydrofuran (THF). Similarly, terpyridine complex 5d was synthesised in the same manner from commercially available terpyridine. These cobalt complexes showed paramagnetically broadened and shifted resonances in the ${ }^{1} \mathrm{H}$ NMR spectra (see ESI $\dagger$ ).

Initial studies focused on the hydroboration of styrene with pinacolborane (1.1 equiv.) using a range of cobalt pre-catalysts (1 $\mathrm{mol} \%$ ) and $\mathrm{NaO}^{t} \mathrm{Bu}(2 \mathrm{~mol} \%)$ as the in situ activator in tetrahydrofuran at room temperature (Table 1). Hydroboration of styrene using ${ }^{\mathrm{H}} \mathrm{BPOCoCl}_{2} \mathbf{5 a}$ and ${ }^{{ }^{s}}{ }^{\mathrm{Bu}} \mathrm{BPOCoCl}_{2} \mathbf{5 b}$ gave the branched hydroboration product in good yield and with 70:30 and $82: 18$ branched: linear regioselectivity, respectively (Table 1, entries 1 and 2). When the more bulky ${ }^{t}{ }^{t} \mathrm{BPOCoCl}_{2} \mathbf{5 c}$ was used, hydroboration of styrene proceeded in excellent yield and with the highest selectivity for the Markovnikov regioisomer (97:3) (Table 1, entry 3). Terpyridine cobalt complex $5 \mathbf{d}$ gave a moderate yield and good Markovnikov regioselectivity (91:1) (Table 1, entry 4). When the hydroboration of styrene, using
Table 1 Reaction optimisation for cobalt-catalysed hydroboration of styrene ${ }^{a}$

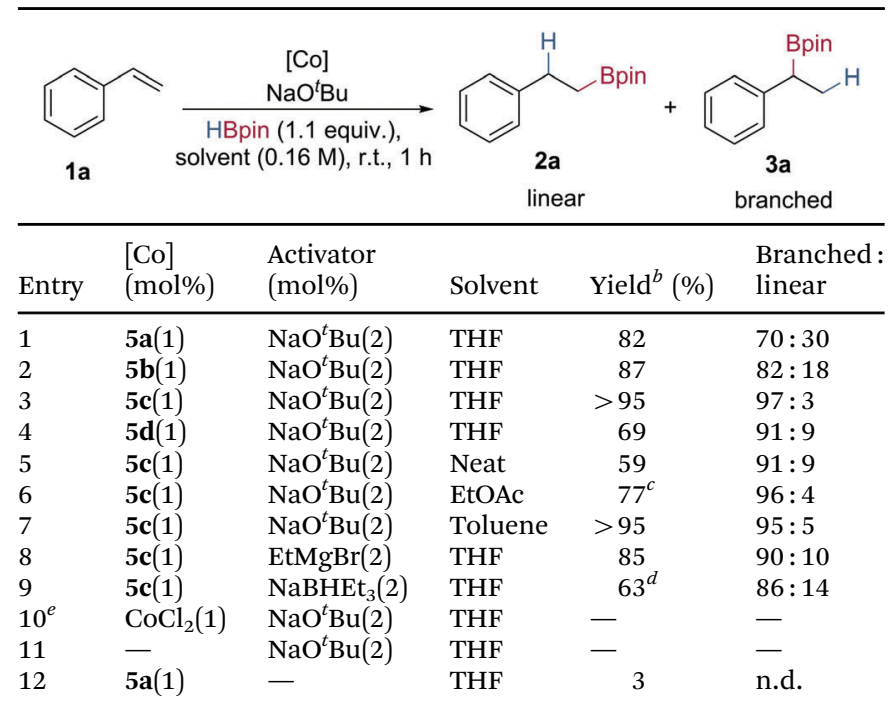

${ }^{a}$ Standard reaction conditions: styrene ( $\left.0.5 \mathrm{mmol}\right)$, HBpin (1.1 equiv.), [Co] $(1.0 \mathrm{~mol} \%)$ and $\mathrm{NaO}^{t} \mathrm{Bu}(2.0 \mathrm{~mol} \%)$ in THF $(3 \mathrm{ml})$ at $25^{\circ} \mathrm{C} .{ }^{b}$ Yields determined by ${ }^{1} \mathrm{H}$ NMR using 1,3,5-trimethoxybenzene as the internal standard. ${ }^{c} 2 \%$ hydrogenation product observed. ${ }^{d} 5 \%$ hydrogenation product observed. ${ }^{e} 30 \%$ hydrogenation product observed.

${ }^{t}{ }^{\mathrm{Bu}} \mathrm{BPOCoCl}_{2} \mathbf{5 c}$, was performed in the absence of solvent, good Markovnikov selectivity ( $91: 1 \mathrm{~b} / \mathrm{l}$ ) was also achieved, but with decreased yield (Table 1, entry 5). Hydroboration of styrene proceeded well in ethyl acetate and toluene, albeit in reduced yield and regioselectivity compared to that in THF (Table 1, entries 6 and 7). Catalyst activation in situ with EtMgBr and $\mathrm{NaBHEt}_{3}$ gave both lower yields and regioselectivities compared to the activation using $\mathrm{NaO}^{t} \mathrm{Bu}$ (Table 1, entries 8 and 9). A control reaction using non-ligated anhydrous $\mathrm{CoCl}_{2}$ under the optimised reaction conditions, showed no catalytic activity (Table 1, entry 10). Similarly, the reaction did not proceed in the absence of cobalt pre-catalyst or without added $\mathrm{NaO}^{t} \mathrm{Bu}$ (Table 1, entries 11 and 12).

Using the optimised reaction conditions, the substrate scope of the Markovnikov selective hydroboration was explored using a range of electronically and sterically differentiated styrene derivatives (Table 2). Hydroboration of styrene gave the secondary boronic ester in excellent isolated yield, and a $97: 3$ branched : linear selectivity (3a, 90\%). Styrene derivatives bearing electron-donating groups such as iso-propyl, tert-butyl and methyl underwent successful hydroboration in excellent yield and regioselectivity (3b-3e, 72-87\%). 4-Phenylstyrene gave the secondary boronic ester in good yield and regioselectivity (3f, 88\%). Styrene derivatives bearing electron-withdrawing substituents including fluoro-, chloro-, bromo- and trifluoromethyl- also underwent successful hydroboration, giving the secondary boronic esters in moderate to excellent yields, with no cleavage of aryl-halide bond observed (3g-3l, 45-92\%). ${ }^{19,20}$ Styrene derivatives bearing trialkylsilyl- and ether substituents also underwent successful hydroboration in good yields and selectivities to give the branched boronic esters (3m-3o, 70-87\%). 
Table 2 Cobalt-catalysed Markovnikov selective hydroboration of vinylarenes using $5 c$

\begin{tabular}{|c|c|}
\hline $\begin{array}{c}5 \mathrm{c}(1.0 \mathrm{~mol} \%) \\
\mathrm{NaO} \mathrm{O}^{t} \mathrm{Bu}(2.0 \mathrm{~mol} \%)\end{array}$ & \\
\hline $\overrightarrow{\text { HBpin (1.1 equiv.), }}$ & \\
\hline $\operatorname{THF}(0.16 \mathrm{M})$, r.t., $1 \mathrm{~h}$ & $x$ \\
\hline
\end{tabular}<smiles>CC(C)c1ccc(C(C)Cc2ccccc2)cc1</smiles>

3b $90 \%$ (81\%) (>98:2)

(97:3)

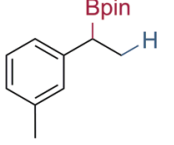

3d $83 \%(79 \%)$

(97:3)<smiles>Fc1ccccc1C(Br)CBr</smiles>

$3 g>95 \%(91 \%)$ (95:5)

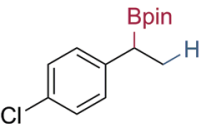

3j $88 \%(79 \%)$ $(85: 15)$<smiles>C[Si](C)(C)c1ccc(C(Cc2ccccc2)Cc2ccccc2)cc1</smiles>

3m 95\% (87\%) $(97: 3)$

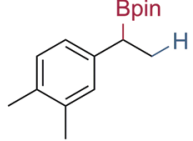

3e $80 \%(72 \%)$

(95:5)

Bpin

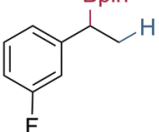

3h >95\% (90\%) (>98:2)

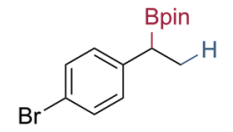

3k $52 \%$ (45\%) (96:4)

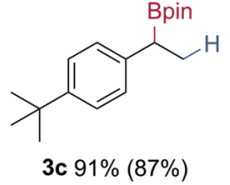

$(97: 3)$

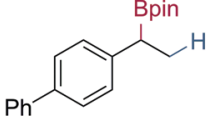

3f $93 \%(88 \%)$

(98:2)

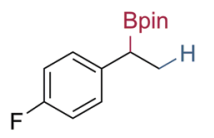

3i >95\% (92\%)

(96:4)

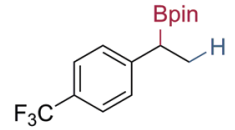

3I $84 \%(80 \%)$ (94:6)<smiles>COc1ccc(C(Cc2ccccc2)c2ccccc2)cc1</smiles>

3n $85 \%(74 \%)$ (88:12)<smiles>C=CC(Cc1ccccc1)c1ccc(N)cc1</smiles>
(75.25)<smiles>C=CC(c1ccccc1)c1ccc(OC(C)=O)cc1</smiles>

3s $90 \%(79 \%)$ (98:2)<smiles>BrCC1Cc2ccccc2C1</smiles>

3v $90 \%(79 \%)$

$(>98: 2)$<smiles>C=CC(c1ccccc1)c1ccc(N(C)C)cc1</smiles>

(86:14)
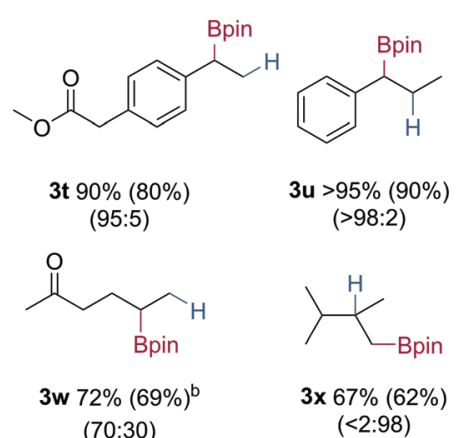

Conditions: alkene $(0.5 \mathrm{mmol}), \mathrm{HBpin}$ (1.1 equiv.), $5 \mathrm{c}(1.0 \mathrm{~mol} \%)$ and $\mathrm{NaO}{ }^{t} \mathrm{Bu}(2.0 \mathrm{~mol} \%)$ in THF $(3 \mathrm{~mL})$ at $25^{\circ} \mathrm{C}, 1 \mathrm{~h}$. Yield was determined by ${ }^{1} \mathrm{H}$ NMR analysis using 1,3,5-trimethoxybenzene as an internal standard. Isolated yields in parentheses. Branched: linear ratios determined from integrals of product peaks in ${ }^{1} \mathrm{H}$ NMR of crude reaction mixtures. ${ }^{a}$ Product decomposed on $\mathrm{SiO}_{2} \cdot{ }^{b} 10 \%$ alkene hydrogenation product observed in the crude reaction mixture. ${ }^{c} 8 \%$ alkene hydrogenation product observed in the crude reaction mixture.
Hydroboration of primary and tertiary amine substituted substrates both gave the secondary boronic ester in good regioselectivity and yield (3p-3q, 83-85\%). Styrene derivatives containing more than one unsaturated group, such as ester and nitrile substituents, were chemoselectively hydroborated at the alkene in excellent yield and regioselectivity, with no observed $\mathrm{C}-\mathrm{O}$ or $\mathrm{C}-\mathrm{N}$ bond cleavage, or reduction (3r-3t, 69-80\%). ${ }^{21}$ Styrene derivatives bearing substituents at the $\beta$-position, such as trans$\beta$-methylstyrene and indene were also reactive under the developed conditions, giving the product boronic esters with complete control of regioselectivity and in excellent yield (3u-3v, 79-90\%). For alkyl alkenes, ketone containing alkene 1w successfully gave the branched boronic ester $3 \mathbf{w}$ in good yield with moderate regioselectivity and without ketone reduction. Hydroboration of 2,3-dimethyl-1-butene $\mathbf{1} \mathbf{x}$ gave the linear boronic ester $\mathbf{3 x}$ in good yield. Presumably, increased steric bulk of the 1,1-disubstituted alkene led to the anti-Markovnikov regioisomer. Oxidation of the secondary boronic ester products to the corresponding alcohols, and analysis by chiral HPLC, showed no enantioselectivity, indicating no stereoinduction from the ligand.

In order to gain insight into the mechanism of the Markovnikov selective hydroboration of vinylarenes with HBpin, deuterium labelling experiments were performed. When the hydroboration of styrene was carried out in $d_{8}$-THF, only the fully protio-boronic ester 3a was obtained, indicating that both $\mathrm{H}$ and Bpin originate from pinacolborane (Scheme 3A). When the hydroboration of $d_{8}$-styrene with HBpin was performed in THF, the mono-protioboronic ester $d_{8}$-3a was formed exclusively with ' $\mathrm{H}$ ' at the terminal methyl group (Scheme 3B). When DBpin (96\% D-content) was used in the hydroboration of styrene, a mixture of mono-deuterated boronic ester $d_{1}$-3a and fully protio-boronic ester $3 \mathbf{a}$ was formed, in a ratio of $88: 12 \mathrm{D} / \mathrm{H}$ (Scheme $3 \mathrm{C}$ ). The presence of (fully) protio-3a presumably arises from either $\beta$-hydride elimination of an intermediate organo-cobalt species, ${ }^{22}$ to generate a cobalt hydride that serves to add ' $\mathrm{H}$ ' to styrene 1a, or H/D exchange with extraneous water, either present in the reaction medium or on work-up.
A<smiles>C=Cc1ccccc1</smiles>

B<smiles>[2H]C([2H])=C([2H])[13CH2]</smiles>
$d_{8}-1 \mathrm{a}$<smiles>C=Cc1ccccc1</smiles>

$1 \mathrm{a}$

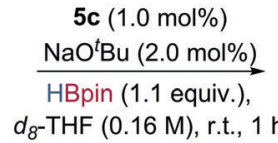

$d_{8}$ THF $(0.16 \mathrm{M})$, r.t., $1 \mathrm{~h}$

5c $(1.0 \mathrm{~mol} \%)$

$\frac{\mathrm{NaO}{ }^{t} \mathrm{Bu}(2.0 \mathrm{~mol} \%)}{\mathrm{HBpin}(1.1 \text { equiv. })}$

$\operatorname{THF}(0.16 \mathrm{M})$, r.t., $1 \mathrm{~h}$

THF (0.16 M), r.t., 1 h

5 c $(1.0 \mathrm{~mol} \%)$ $\mathrm{NaO}^{t} \mathrm{Bu}(2.0 \mathrm{~mol} \%)$ DBpin ( $96 \% D, 1.1$ equiv.),

$\operatorname{THF}(0.16 \mathrm{M})$, r.t., $1 \mathrm{~h}$

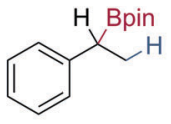

$3 a$ $97: 3 \mathrm{~b} / \mathrm{l}, 91 \%$

$$
\underset{\substack{d_{5} \\ 97: 3 \mathrm{~b} / \mathrm{Ph}, 75 \%}}{d_{8^{-3}}^{\mathrm{Bppin}}}
$$

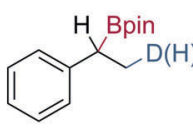

$88: 12 d_{1}-3 \mathbf{a} / 3 \mathbf{a}$ 98:2 b/l, 70\%
Scheme 3 Deuterium labelling studies of Markovnikov selective styrene hydroboration; isolated yields following flash column chromatography. 
In conclusion, we have developed a Markovnikov selective cobalt-catalysed hydroboration of alkenes with pinacolborane at ambient temperature, using a bench-stable cobalt pre-catalyst bearing a bipyridiyl-oxazoline ligand. This strategy has been applied to a variety of electronically and sterically differentiated styrene derivatives, bearing a range of functional groups, to give the secondary boronic esters in both high yield and regioselectivity.

S. P. T. acknowledges the University of Edinburgh for a Chancellor's Fellowship and the Royal Society for a University Research Fellowship and a Research Grant. J. P. acknowledges the University of Edinburgh and China Scholarship Council for a joint scholarship. J. H. D. and S. P. T. acknowledge GlaxoSmithKline and the EPSRC (EP/M506515/1) for a PhD studentship.

\section{Notes and references}

1 (a) H. C. Brown, Organic Synthesis via Boranes, Wiley, New York, 1975; (b) H. C. Brown and B. Singaram, Pure Appl. Chem., 1987, 59, 879; (c) Science of Synthesis: Vol. 6, Boron Compounds, ed. D. E. Kaufmann and D. S. Matteson, Georg Thieme Verlag, Stuttgart-New York, 2004; (d) Boronic Acids: Preparation and Applications in Organic Synthesis and Medicine, ed. D. G. Hall, Wiley-VCH, Weinheim, 2005.

2 (a) K. Burgess and M. J. Ohlmeyer, Chem. Rev., 1991, 91, 1179; (b) I. Beletskaya and A. Pelter, Tetrahedron, 1997, 53, 4957; (c) C. M. Crudden and D. Edwards, Eur. J. Org. Chem., 2003, 4695.

3 M. D. Greenhalgh, A. S. Jones and S. P. Thomas, ChemCatChem, 2014, 6, 1520.

4 I. Bauer and H.-J. Knölker, Chem. Rev., 2015, 115, 3170.

5 L. Zhang, D. Peng, X. Leng and Z. Huang, Angew. Chem., Int. Ed., 2013, 52, 3676.
6 J. V. Obligacion and P. J. Chirik, J. Am. Chem. Soc., 2013, 135, 19107.

7 W. N. Palmer, T. Diao, I. Pappas and P. J. Chirik, ACS Catal., 2015, $5,622$.

8 S. W. Reilly, C. E. Webster, T. K. Hollis and H. U. Valle, Dalton Trans., 2016, 45, 2823.

9 M. L. Scheuermann, E. J. Johnson and P. J. Chirik, Org. Lett., 2015, 17, 2716.

10 M. D. Greenhalgh and S. P. Thomas, Chem. Commun., 2013, 49, 11230.

11 J. Chen, T. Xi and Z. Lu, Org. Lett., 2014, 16, 6452.

12 A. J. MacNair, C. R. P. Millet, G. S. Nichol, A. Ironmonger and S. P. Thomas, ACS Catal., 2016, 6, 7217.

13 M. Espinal-Viguri, C. R. Woof and R. L. Webster, Chem. - Eur. J., 2016, 22, 11605.

14 J. Chen, T. Xi, X. Ren, B. Cheng, J. Guo and Z. Lu, Org. Chem. Front., $2014,1,1306$.

15 T. Xi and Z. Lu, ACS Catal., 2017, 7, 1181.

16 E. E. Touney, R. Van Hoveln, C. T. Buttke, M. D. Freidberg, I. A. Guzei and J. M. Schomaker, Organometallics, 2016, 35, 3436.

17 S. Krautwald, M. J. Bezdek and P. J. Chirik, J. Am. Chem. Soc., 2017, 139, 3868.

18 J. H. Docherty, J. Peng, A. P. Dominey and S. P. Thomas, Nat. Chem., DOI: $10.1038 /$ nchem.2697.

19 T. Hatakeyama, Y. Kondo, Y. Fujiwara, H. Takaya, S. Ito, E. Nakamura and N. Nakamura, Chem. Commun., 2009, 1216.

20 W. M. Czaplik, S. Grupe, M. Mayer and A. Jacobi von Wangelin, Chem. Commun., 2010, 46, 6350.

21 R. J. Trovitch, E. Lobkovsky, M. W. Bouwkamp and P. J. Chirik, Organometallics, 2008, 27, 6264.

22 It should be noted that we were unable to observe any products of $\mathrm{H} / \mathrm{D}$ scrambling consistent with this scenario (e.g. $d_{n}$-styrene) in the crude reaction mixtures, but this may be due to loss of these low boiling point products on work-up. 